\title{
Application and Recent Trends in Implementation of Internet of Things: A comprehensive review
}

\author{
Mr. S. Karthik \\ Ph.D - Research Scholar, \\ Anna University, Chennai \\ skarthik.mcs16@gmail.com \\ Dr. N. Satish \\ Professor and Head, \\ Department of Information Technology, Mahendra College of Engineering, Salem \\ satishmail12@gmail.com
}

\begin{abstract}
:
Internet of Things (IoT) is an evolving technology in the current era with a combination of diverse computational technologies, objects, animals and human. The objects in the IoT framework transmit data among themselves and they are assigned with unique numbers for identification. The communication among the network is established by identification system and functions without any centralized system. Advancement in the sensor network has made automation in numerous field and integration of soft computing technology in the IoT system has made effective decision making. The objects resides in the IoT system acts intelligent and perform the actions intelligently. The IoT based technology enhances daily life of humans via connected devices and makes living things context-aware. The information collected from sensors will be processed with the computational algorithms and effective predictions are accomplished. In this article, recent applications and soft computing algorithms are reviewed. In addition to that numerous applications based on IoT is also discussed in this article.
\end{abstract}

Keywords: Machine learning, deep learning, IoT, intelligent object, healthcare, and automation. 


\section{Introduction}

The essence of IoT relies on the perception of huge variety of devices, which are interconnected and exchange information among the framework of IoT [1]. It determines the capability of interconnected devices and the interaction with other devices as well as users over the infrastructure of the network. IoT brings seamless integration among the object across the world. In today's world, the advancement of technology has made IoT devices are necessary and turned as a part of human life experience $[2,3]$.

In the framework of IoT, every device is interconnected with other devices in the network that communicates, transmits, retrieve data and triggers the actions intelligently. IoT technology has reduced the manpower in several fields and it can enhance the proficiency in manufacturing, transportation, smart education and innovative technologies [4, 5]. The progression in IoT enriches the development of start-ups in manufacturing, new industries, automation, cloud computing, cyber-security, artificial intelligence, and machine learning. One of the biggest complication in the incorporation of IoT is adoption. There are several descriptions and portrayals for IoT by diverse researchers, companies, and authors [5].

IoT acquires entire potential support by using the chief role intelligent object that utilizes several sensors and actuators. Object relies in the IoT system can perceive the context of the atmospheric condition. With the acquired data, the ability of the network is developed to process the service and communicate with the world. The paradigm of IoT makes the whole world as interconnected to accomplish the comfortable and safe real-time scenario. Advent of IoT has influenced numerous domains and has prominent role in the disaster management [6] and healthcare [7].

Numerous IoT products namely tracking system with fitness shoes, wearable bands for monitoring the health, smart meters, smart devices with RFID technology, real-time monitoring equipment's, and other smart devices implanted with IoT technology. Additionally, IoT application with smartphone technology provide assistance in tracking the humans and the necessary alerts can be generated [8]. The biological sensor collect the physiological information from the humans and process the gathered data with the computational algorithms. The necessary actions are taken based on the processed sensory information [9].

The robustness of IoT has made the possibility of gathering real-time sensor information from diverse sources for long duration that is simple and fast. The physiological information along with the atmospheric information are gathered and the data is processed by the computational algorithms which in turn provide the status of the every individual uses. There are numerous sensor available for recording the physiological signs namely oxygen, pulse rate, heart rate, the level of glucose in blood and pressure in blood [10, 11].

The sensors can precisely measure, store, analyse and observe the status of the every individual user. Reliable and innovative techniques of IoT accomplish the tasks in reduced time 
with high benefit. The potential of IoT is ever-increasing and unlimited, which has huge impact on the society and also influences the daily life style, strategies used in business and in the industrial production. Effective machine learning [12], deep learning [13] and optimization techniques [14] makes the effective use of IoT technology [15].

The remaining of the paper is organized as follows: available bio sensors and their relevancy in current world is explained in Section 2, the applications and recent trends in IoT is discussed in Section 3, the machine learning based data analysis is given in Section 4 and the article is concluded in Section 5.

\section{Varieties of Biosensors and their Applications}

Biosensor is a group of physicochemical and biological element where the devices are developed to observe the biological scenario. Biosensor is utilised to identify the anlyte and generate determined signals. Biosensor based application is one of the capable technology established for examining and observing the status in numerous sectors. Over a decade, several bio-sensing associated devices have been established to meet the complications confronted by numerous applications and they will generate accurate results.

The biological signals are gathered by the biological sensor, which is transformed into electronic signals. This transformation is a challenging mission due to the complexity in the electronic device that is directly assigned with biological framework. Biosensors have immense application in monitoring of environmental, quality checking in food industry, marine, industry, diagnosis in clinic, and other areas whichever necessitated accurate and reliable analyses.

Detection of glucose level and pregnancy identification are attained by the biosensors. Biosensor based application deliver enhanced stability and accurate results as compared to the traditional techniques. Recent progression in fluorescent spectroscopy, materials, nanotechnology and biology have escalated the potential detection scheme of multi-marker, and sensitive detection of diverse diseases via single device [16]. Some of the applications and their usage is given as follows,

Food processing industry, observing the context industry, checking the authenticity of food, safety and quality measurement.

The processes of fermentation and observing the context.

Bio-sensing technology for maintainable food protection.

Biosensors in medical field and in smart hospitals. 
Fluorescent biosensors for the forecast of protein function.

Biodefense applications for safety assurance and biosensors in plant biology for observing the condition of crop.

\section{Application and Recent Trends in IoT}

Smart wearables gather information and analyse the data, and in certain context smart decisions are taken from the processed sensor data. Based on the decision taken from the processing, needed response is delivered to the user. IoT-enabled wearable devices are considered as smart device and it can be worn externally as an accessories that can be embedded in garments, clothing, adhered with skin or tattooed and implanted with body. These wearable devices are interconnected with the Internet to gather, send and receive data that is further utilised in making smart decisions.

Wearables are significant portion in IoT and their progression is switching from simple to specialized applications. The smart wearables uses the wear-sense technology and it can interact with other array of devices namely computing technology, smart gadgets and communication paradigm. Due to the animals and humans mobility, smart wearable are turned as significant since they can gather and transmit the data over internet that provide high assistance in decisions smartly. The utilization of wearables can efficiently progress and optimize the application.

Smart wearables has the ability to enrich the quality of life, improves the safety and production. The progression of mobile network with less power, minimization in the electronic device size and sensor has made the increased usage of wearable technology. The rapid progression is witnessed in the wearable products that is adopted for numerous application during past few years. Wrist bands, smart watches, headsets, eye wears, body straps, ear buds, smart accessories, hand and foot worn devices are the few of the wearables for diverse applications. This technology also utilised in the gaming field and automation. However, the significant life-modifying application in wearable technology is identified mostly in the medical use cases and in continuous monitoring of health. The applications and the significant inference are elucidated in Table 1. 
Table 1. Overview of Different IoT Sensors

\begin{tabular}{|c|c|c|c|c|c|c|c|}
\hline $\begin{array}{c}\text { Application } \\
\text { Type }\end{array}$ & Sensor & $\begin{array}{l}\text { Parameter } \\
\text { Sensed }\end{array}$ & \begin{tabular}{|l|} 
Node \\
Process
\end{tabular} & $\begin{array}{c}\text { Mobile } \\
\text { App }\end{array}$ & Wearable & Connectivity & $\begin{array}{l}\text { Refer } \\
\text { ence }\end{array}$ \\
\hline \multirow{4}{*}{ Rehabilitation } & sEMG & $\begin{array}{c}\text { Surface } \\
\text { electromyogra } \\
\text { phy }\end{array}$ & Yes & No & Armband & BLE & {$[17]$} \\
\hline & $\begin{array}{l}\text { Ultra sound, } \\
\text { IMU, RFID } \\
\text { and Load Cell }\end{array}$ & $\begin{array}{c}\text { Force, Orientation } \\
\text { and Distance }\end{array}$ & No & Yes & Walker & tooth and Wi-Fi & {$[18]$} \\
\hline & \begin{tabular}{|c} 
Flex \\
Acceleromet er \\
and \\
gyroscope
\end{tabular} & $\begin{array}{l}\text { Orientation, } \\
\text { Deflection and } \\
\text { Acceleration }\end{array}$ & No & No & nd and Leg & Wi-Fi & [19] \\
\hline & Camera & $\begin{array}{l}\text { Eye blinks and } \\
\text { Face image }\end{array}$ & No & Yes & Face & Wi-Fi & {$[20]$} \\
\hline \multirow{12}{*}{ Monitoring } & $\begin{array}{l}\text { Temperature } \\
\text { and ECG }\end{array}$ & Heart rate & No & Yes & Wristband & Bluetooth & {$[21]$} \\
\hline & SFH 7051 & Heart rate & No & No & Wristband & Wi-Fi & [22] \\
\hline & $\begin{array}{c}\text { Passive } \\
\text { breathing } \\
\text { airflow } \\
\text { temperature } \\
\text { change }\end{array}$ & Respiratory & No & No & Headband & Back Scattering & {$[23]$} \\
\hline & \begin{tabular}{|c|} 
WHMIS \\
inductive \\
sensor and ECG
\end{tabular} & Heart rate & Yes & No & $\begin{array}{l}\text { Thest, Leg and } \\
\text { Hand }\end{array}$ & 2 G GPRS & {$[24]$} \\
\hline & Capacitive & Respiratory & Yes & Yes & Chest & Bluetooth & [25] \\
\hline & $\begin{array}{l}\text { Piezoelectric or } \\
\text { Vibration }\end{array}$ & Respiratory & Yes & No & Headband & $\begin{array}{c}\text { Impulse radio and } \\
\text { ultra wideband } \\
\text { transmitter }\end{array}$ & {$[26]$} \\
\hline & $\begin{array}{c}\text { IC mounted on } \\
\text { tablet shaped } \\
\text { ingestible } \\
\end{array}$ & Temperature & No & No & Finger & $\begin{array}{l}\text { Coupling based } \\
\text { on magnetic }\end{array}$ & {$[27]$} \\
\hline & LM35 & Temperature & No & No & Smart vest & Wi-Fi & [28] \\
\hline & $\begin{array}{c}\text { Pulse } \\
\text { oximetry }\end{array}$ & Blood Oxygen & Yes & No & Bracelet & GSM or GPRS & {$[29]$} \\
\hline & Piezoelectric & \begin{tabular}{|l|} 
Blood \\
Pressure
\end{tabular} & Yes & Yes & Cuff & Wi-Fi & {$[30]$} \\
\hline & $\begin{array}{c}\text { Gyroscope, } \\
\text { audio and } \\
\text { acceleromete } r\end{array}$ & $\begin{array}{c}\text { Mental } \\
\text { Wellbeing }\end{array}$ & Yes & Yes & Wristband & Bluetooth & {$[31]$} \\
\hline & \begin{tabular}{|c|} 
Near \\
infrared \\
radiation
\end{tabular} & Blood Glucose & No & Yes & Finger & Wi-Fi & {$[32]$} \\
\hline
\end{tabular}

\section{Machine Learning based Data Analysis}

In the perception of AI, accumulated sensor data is stored in the system and the data is utilised in accomplishing entire task that is precise instructions in the sensor data is followed. 
But in the perception of Machine Learning, algorithms are programmed for executing certain task. In other words, ML system will learn the condition of a place and execute accordingly. In Machine Learning, innovative outcome is forecasted from programming and vast amount of input data. The straight commands for decision making are not allowed in this system and it permits the system to learn the nature of the data for making any decision. The sketch of Machine learning with the AI data is enlightened in figure 1.

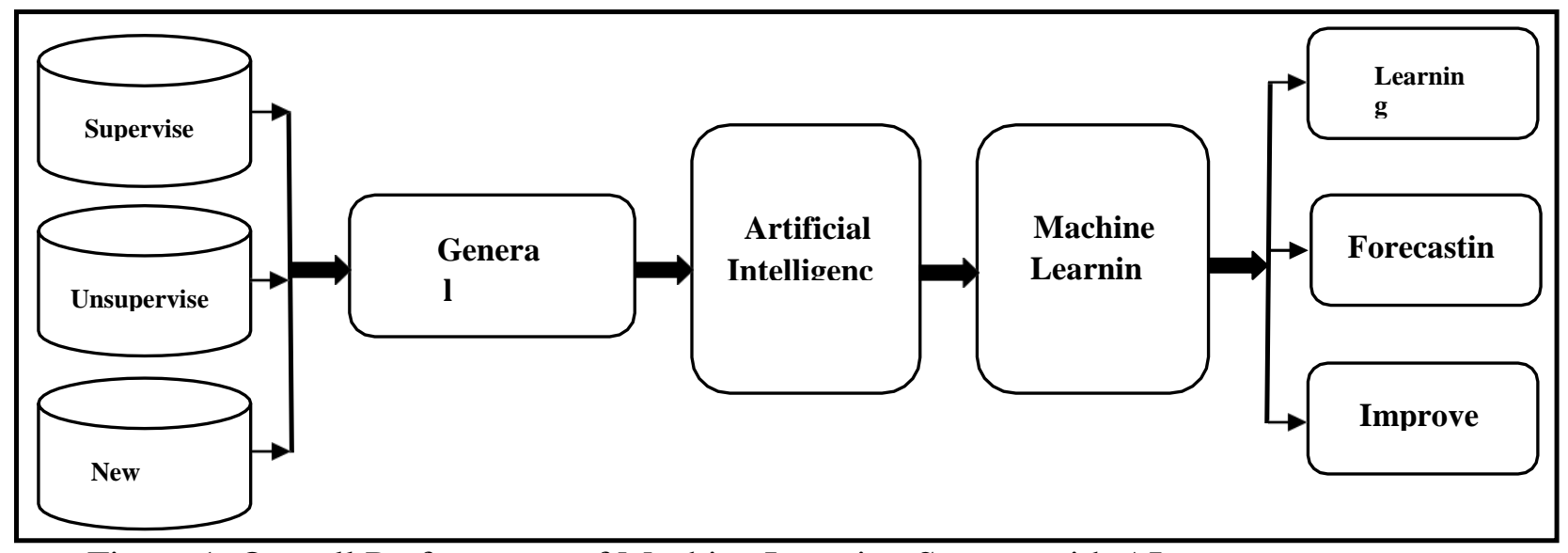

Figure 1. Overall Performance of Machine Learning System with AI

The machine learning algorithms inspects the data to identify the nature of the patterns and to formulate a model, which is then unified into the system to forecast the necessary future values. The progression of machine learning is comprised of three steps, they are data analysation, construction of ML model and undertaking a decision that is presented in figure 2. In the initial step, the input data is utilised for learning and the appropriate model is fabricated. In the following process, decisions are accomplishment from the constructed ML model.

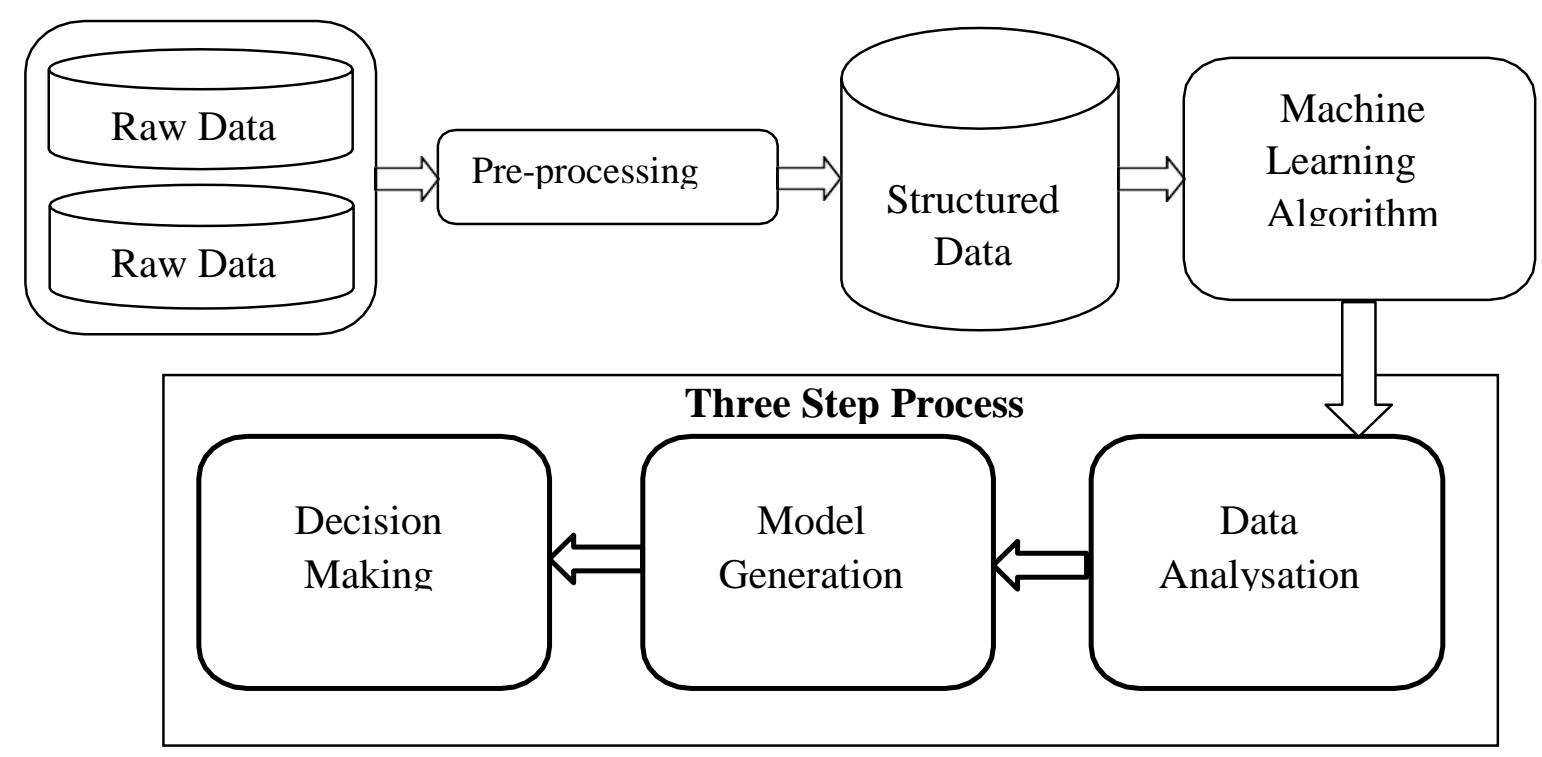

Figure 2. Three Step process of Machine Learning Algorithm 
Numerous existing applications are established based on the machine learning algorithms namely alpha go, google's deep mind and self-driving car. Machine learning and AI act as a identical whereas machine learning is a sub-domain of AI. For example, AI classifies the progression of future stock exchange with the assistance of patterns in the preceding stock data and in machine learning the system acquires the preceding data whereas the forecast is carried based on the condition. In the past decade, AI has exposed the exponentialprogression and regeneration which is due to the substantial improvements in machine learning. The machine learning is classified into three category such as supervised, unsupervised and reinforcement learning.

\section{Supervised learning}

The main intent of supervised learning is identifying the necessary function that associates the data to the appropriate labels. From the finding, new model is built and it is employed to the identical new data. In Facebook, ever photograph is branded with unique label value by the facebook. The algorithm is incorporated in identifying the appropriate peoples in the photograph and the automatic identification is commenced for new data.

\section{Unsupervised learning}

In this unsupervised learning, AI delivers the data that are categorized instead of labelling. The classified data is examined to disclose the necessary hidden patterns. From the representation of the data, new clusters are designed and further these clusters are categorized. Google utilises unsupervised learning to group the customers for posting applicable advertisement based on their latest searches.

\section{Reinforcement learning}

In the supervised and unsupervised learning, the model generation is based on the nature of the data. Once the data alters to new setup and the process of examination is attained to make new model. Reinforcement learning incorporated the continuous learning process to make the model based on the produced feedback. The reinforcement based model is iteratively established that is endlessly learned and progressed. The summarization of ML techniques in the IoT use cases are given in Table 2. 
Table 2. Summarization of Machine Learning techniques in the incorporation into the use case of Internet of Things

\begin{tabular}{|c|c|c|c|}
\hline $\begin{array}{c}\text { Machine Learning } \\
\text { technique }\end{array}$ & Use Cases & Optimized Metrics & Reference \\
\hline Classification & Smart Traffic & $\begin{array}{l}\text { Forecasting of traffic and Data } \\
\text { abbreviation is increased }\end{array}$ & {$[33,34]$} \\
\hline ntification of Anomaly & hvironment and Traffic & $\begin{array}{l}\text { Identification of anomalies in power dataset, } \\
\text { Forecasting of traffic and Data } \\
\text { abbreviation is increased }\end{array}$ & $\begin{array}{c}{[33,34,} \\
35]\end{array}$ \\
\hline Clustering & Smart Health and Traffic & $\begin{array}{l}\text { Forecasting of traffic and Data } \\
\text { abbreviation is increased }\end{array}$ & $\begin{array}{c}{[33,34,} \\
36]\end{array}$ \\
\hline Linear Regression & $\begin{array}{l}\text { Usage of Energy, analysis } \\
\text { of market and economics }\end{array}$ & $\begin{array}{c}\text { Forecasting by real-time and quantity of } \\
\text { data is reduced }\end{array}$ & {$[37,38]$} \\
\hline $\begin{array}{l}\text { Support Vector } \\
\text { Regression }\end{array}$ & Smart Weather Forecasting & Forecasting & [39] \\
\hline $\begin{array}{l}\text { Support Vector } \\
\text { Machine }\end{array}$ & All use cases & $\begin{array}{c}\text { Data classification and forecasting by real- } \\
\text { time }\end{array}$ & {$[40,37]$} \\
\hline $\begin{array}{l}\text { Regression Tree and } \\
\text { Classification }\end{array}$ & Smart Citizens & $\begin{array}{l}\text { sting by real-time and travel patter } \\
\text { identification of passengers }\end{array}$ & {$[37,41]$} \\
\hline Naïve Bayes & art Citizens and Agriculture & $\begin{array}{c}\text { Travel patter identification of passengers, } \\
\text { food safety and calculating the count of the } \\
\text { nodes }\end{array}$ & $\begin{array}{c}{[42,41,} \\
43]\end{array}$ \\
\hline $\begin{array}{l}\text { K-Nearest } \\
\text { Neighbor }\end{array}$ & Smart Citizens & $\begin{array}{l}\text { Travel patter identification of passengers } \\
\text { and learned metric efficiency }\end{array}$ & {$[41,44]$} \\
\hline $\begin{array}{l}\text { Density based } \\
\text { Clustering }\end{array}$ & Smart Citizens & $\begin{array}{c}\text { Travel patter identification of passengers, } \\
\text { data labeling and detection of fraud }\end{array}$ & $\begin{array}{c}{[40,45,} \\
41]\end{array}$ \\
\hline K-Means & $\begin{array}{c}\text { Air Control, Smart Citizen, } \\
\text { Smart City, Smart Traffic, and } \\
\text { Smart Home }\end{array}$ & $\begin{array}{l}\text { Travel patter identification of passengers, } \\
\text { small dataset analysation, datastream } \\
\text { analysation, predicting the consumption of } \\
\text { energy, detection of fraud and outlier }\end{array}$ & $\begin{array}{l}{[46,45,} \\
47,48,41, \\
49]\end{array}$ \\
\hline \begin{tabular}{|l} 
Principal Component \\
Analysis
\end{tabular} & Public place monitoring & Detection of fault & [50] \\
\hline $\begin{array}{l}\text { Feed Forward Neural } \\
\text { Network }\end{array}$ & Smart Health & $\begin{array}{l}\text { Energy consumption minimization, } \\
\text { element states are forecasted, redundancy of } \\
\text { the data and information is rectified }\end{array}$ & $\begin{array}{c}{[51,43,} \\
38]\end{array}$ \\
\hline \begin{tabular}{|l} 
One Class Support \\
Vector Machines
\end{tabular} & $\begin{array}{l}\text { Smart Human Activity } \\
\text { Control } \\
\end{array}$ & $\begin{array}{l}\text { Detection of fraud and emerging } \\
\text { anomalies in the data }\end{array}$ & {$[45,54]$} \\
\hline $\begin{array}{l}\text { Canonical Correlation } \\
\text { Analysis }\end{array}$ & Public place monitoring & Detection of fault & [50] \\
\hline
\end{tabular}

\section{Conclusion}

Internet of Things (IoT) is a developing technology in the current era with a combination of diverse computational technologies, objects, animals and human. Advent of IoT made the work simple and easy to do. The objects reside inside the IoT system act intelligently and make decisions based on the need. IoT is widely accepted in numerous applications and effective results were acquired. The information collected from sensors will be processed with the 
computational algorithms and effective predictions are accomplished. In this article, recent applications and soft computing algorithms are reviewed. In addition to that numerous applications based on IoT is also discussed in this article. The data gathered from sensor applications are processed with effective machine learning approached where the significant decisions are taken by the sensor data.

\section{Reference}

[1]. Saha, H. N., Mandal, A., \& Sinha, A. (2017, January). Recent trends in the Internet of Things. In 2017 IEEE 7th annual computing and communication workshop and conference $(C C W C)$ (pp. 1-4). IEEE.

[2]. Saha, H. N., Saha, N., Ghosh, R., \& Roychoudhury, S. (2016, October). Recent trends in implementation of Internet of Things-A review. In 2016 IEEE 7th Annual Information Technology, Electronics and Mobile Communication Conference (IEMCON) (pp. 1-6). IEEE.

[3]. Ning, H., \& Hu, S. (2012). Technology classification, industry, and education for Future Internet of Things. International journal of communication systems, 25(9), 1230-1241.

[4]. Li, S., Da Xu, L., \& Zhao, S. (2018). 5G Internet of Things: A survey. Journal of Industrial Information Integration, 10, 1-9.

[5]. Mendez Mena, D., Papapanagiotou, I., \& Yang, B. (2018). Internet of things: Survey on security. Information Security Journal: A Global Perspective, 27(3), 162-182.

[6]. Kodali, R. K., Swamy, G., \& Lakshmi, B. (2015, December). An implementation of IoT for healthcare.

In 2015 IEEE Recent Advances in Intelligent Computational Systems (RAICS) (pp. 411-416). IEEE.

[7]. Kodali, R. K., Swamy, G., \& Lakshmi, B. (2015, December). An implementation of IoT for healthcare.

In 2015 IEEE Recent Advances in Intelligent Computational Systems (RAICS) (pp. 411-416). IEEE.

[8]. Niitsu, K., Kobayashi, A., Nishio, Y., Hayashi, K., Ikeda, K., Ando, T., ... \& Nakazato, K. (2018). A self- powered supply-sensing biosensor platform using bio fuel cell and lowvoltage, low-cost CMOS supply- controlled ring oscillator with inductive-coupling transmitter for healthcare IoT. IEEE Transactions on Circuits and Systems I: Regular Papers, 65(9), 2784-2796.

[9]. Yang, G., Xie, L., Mäntysalo, M., Zhou, X., Pang, Z., Da Xu, L., ... \& Zheng, L. R. (2014). A health-IoT platform based on the integration of intelligent packaging, unobtrusive biosensor, and intelligent medicine box. IEEE transactions on industrial informatics, 10(4), 2180-2191.

[10]. Prakash, R., \& Ganesh, A. B. (2019). Internet of Things (IoT) enabled wireless sensor network for physiological data acquisition. In International Conference on Intelligent Computing and Applications (pp. 163-170). Springer, Singapore.

[11]. Haghi, M., Neubert, S., Geissler, A., Fleischer, H., Stoll, N., Stoll, R., \& Thurow, K. (2020). A Flexible and Pervasive IoT-Based Healthcare Platform for Physiological and Environmental Parameters Monitoring. IEEE Internet of Things Journal, 7(6), 5628-5647. 
[12]. Hussain, F., Hussain, R., Hassan, S. A., \& Hossain, E. (2020). Machine learning in IoT security: Current solutions and future challenges. IEEE Communications Surveys \& Tutorials, 22(3), 1686-1721.

[13]. Mohammadi, M., Al-Fuqaha, A., Sorour, S., \& Guizani, M. (2018). Deep learning for IoT big data and streaming analytics: A survey. IEEE Communications Surveys \& Tutorials, 20(4), 2923-2960.

[14]. Hamidouche, R., Aliouat, Z., Ari, A. A. A., \& Gueroui, M. (2019). An efficient clustering strategy avoiding buffer overflow in IoT sensors: a bio-inspired based approach. IEEE Access, 7, 156733-156751.

[15]. Lee, I., \& Lee, K. (2015). The Internet of Things (IoT): Applications, investments, and challenges for enterprises. Business Horizons, 58(4), 431-440.

[16]. Malima, A., Siavoshi, S., Musacchio, T., Upponi, J., Yilmaz, C., Somu, S., \& Busnaina, A. (2012). Highly sensitive microscale in vivo sensor enabled by electrophoretic assembly of nanoparticles for multiple biomarker detection. Lab on a Chip, 12(22), 4748-4754.

[17]. Yang, G., Deng, J., Pang, G., Zhang, H., Li, J., Deng, B., \& Yang, H. (2018). An IoTenabled stroke rehabilitation system based on smart wearable armband and machine learning. IEEE journal of translational engineering in health and medicine, 6, 1-10.

[18]. Postolache, O., Hemanth, D. J., Alexandre, R., Gupta, D., Geman, O., \& Khanna, A. (2020). Remote monitoring of physical rehabilitation of stroke patients using IoT and virtual reality. IEEE Journal on Selected Areas in Communications, 39(2), 562-573.

[19]. Agyeman, M. O., \& Al-Mahmood, A. (2019, June). Design and implementation of a wearable device for motivating patients with upper and/or lower limb disability via gaming and home rehabilitation. In 2019 Fourth International Conference on Fog and Mobile Edge Computing (FMEC) (pp. 247-252). IEEE.

[20]. Ghorbel, A., Bouguerra, S., Amor, N. B., \& Jallouli, M. (2018, June). Cloud based mobile application for remote control of intelligent wheelchair. In 2018 14th International Wireless Communications \& Mobile Computing Conference (IWCMC) (pp. 1249-1254). IEEE.

[21]. Majumder, A. K. M., ElSaadany, Y. A., Young, R., \& Ucci, D. R. (2019). An energy efficient wearable smart IoT system to predict cardiac arrest. Advances in Human-Computer Interaction, 2019.

[22]. Jayanth, S., Poorvi, M. B., Shreyas, R., Padmaja, B., \& Sunil, M. P. (2017, January). Wearable device to measure heart beat using IoT. In 2017 International Conference on Inventive Systems and Control (ICISC) (pp. 1-5). IEEE.

[23]. Milici, S., Lorenzo, J., Lazaro, A., Villarino, R., \& Girbau, D. (2016). Wireless breathing sensor based on wearable modulated frequency selective surface. IEEE Sensors Journal, 17(5), 1285-1292.

[24]. Brezulianu, A., Geman, O., Zbancioc, M. D., Hagan, M., Aghion, C., Hemanth, D. J., \& Son, L. H. (2019). IoT based heart activity monitoring using inductive sensors. Sensors, 19(15), 3284.

[25]. Naranjo-Hernández, D., Talaminos-Barroso, A., Reina-Tosina, J., Roa, L. M., BarbarovRostan, G., Cejudo-Ramos, P., \& Ortega-Ruiz, F. (2018). Smart vest for respiratory rate monitoring of COPD patients based on non-contact capacitive sensing. Sensors, 18(7), 2144.

[26]. Mahbub, I., Pullano, S. A., Wang, H., Islam, S. K., Fiorillo, A. S., To, G., \& Mahfouz, M. R. (2017). A low-power wireless piezoelectric sensor-based respiration monitoring system 
realized in CMOS process. IEEE Sensors Journal, 17(6), 1858-1864.

[27]. Yoshida, S., Miyaguchi, H., \& Nakamura, T. (2018). Development of tablet-shaped ingestible core-body thermometer powered by gastric acid battery. IEEE Sensors Journal, 18(23), 9755-9762.

[28]. Wan, J., Al-awlaqi, M. A., Li, M., O’Grady, M., Gu, X., Wang, J., \& Cao, N. (2018). Wearable IoT enabled real-time health monitoring system. EURASIP Journal on Wireless Communications and Networking, 2018(1), 1-10.

[29]. Murali, D., Rao, D. R., Rao, S. R., \& Ananda, M. (2018, September). Pulse oximetry and IOT based cardiac monitoring integrated alert system. In 2018 international conference on advances in computing, communications and informatics (ICACCI) (pp. 2237-2243). IEEE.

[30]. Lamonaca, F., Balestrieri, E., Tudosa, I., Picariello, F., Carnì, D. L., Scuro, C., ... \& Colaprico, A. (2019, June). An overview on Internet of medical things in blood pressure monitoring. In 2019 IEEE International Symposium on Medical Measurements and Applications (MeMeA) (pp. 1-6). IEEE.

[31]. Yang, S., Gao, B., Jiang, L., Jin, J., Gao, Z., Ma, X., \& Woo, W. L. (2018). IoT structured long-term wearable social sensing for mental wellbeing. IEEE Internet of Things Journal, 6(2), 3652-3662.

[32]. Pradhan, B., Bhattacharyya, S., \& Pal, K. (2021). IoT-Based Applications in Healthcare Devices. Journal of healthcare engineering, 2021.

[33]. Kafi, M. A., Challal, Y., Djenouri, D., Doudou, M., Bouabdallah, A., \& Badache, N. (2013). A study of wireless sensor networks for urban traffic monitoring: applications and architectures. Procedia computer science, 19, 617-626.

[34]. Qin, Y., Sheng, Q. Z., Falkner, N. J., Dustdar, S., Wang, H., \& Vasilakos, A. V. (2016). When things matter: A survey on data-centric internet of things. Journal of Network and Computer Applications, 64, 137- 153.

[35]. Jakkula, V., \& Cook, D. (2010, July). Outlier detection in smart environment structured power datasets.

In 2010 Sixth International Conference on Intelligent Environments (pp. 29-33). IEEE.

[36]. Toshniwal, D. (2013, February). Clustering techniques for streaming data-a survey. In 2013 3rd IEEE international advance computing conference (IACC) (pp. 951-956). IEEE.

[37]. Derguech, W., Bruke, E., \& Curry, E. (2014, December). An autonomic approach to realtime predictive analytics using open data and internet of things. In 2014 IEEE 11th Intl Conf on Ubiquitous Intelligence and Computing and 2014 IEEE 11th Intl Conf on Autonomic and Trusted Computing and 2014 IEEE 14th Intl Conf on Scalable Computing and Communications and Its Associated Workshops (pp. 204-211). IEEE.

[38]. Hu, S. (2015, July). Research on data fusion of the internet of things. In 2015 International Conference on Logistics, Informatics and Service Sciences (LISS) (pp. 1-5). IEEE.

[39]. Ni, P., Zhang, C., \& Ji, Y. (2014, August). A hybrid method for short-term sensor data forecasting in Internet of Things. In 2014 11th International Conference on Fuzzy Systems and Knowledge Discovery (FSKD) (pp. 369-373). IEEE.

[40]. Khan, M. A., Khan, A., Khan, M. N., \& Anwar, S. (2014, November). A novel learning method to classify data streams in the internet of things. In 2014 National Software Engineering Conference (pp. 61- 66). IEEE.

[41]. Ma, X., Wu, Y. J., Wang, Y., Chen, F., \& Liu, J. (2013). Mining smart card data for transit 
riders' travel patterns. Transportation Research Part C: Emerging Technologies, 36, 1-12.

[42]. Han, W., Gu, Y., Zhang, Y., \& Zheng, L. (2014, October). Data driven quantitative trust model for the internet of agricultural things. In 2014 International Conference on the Internet of Things (IOT) (pp. 31-36). IEEE.

[43]. Kotenko, I., Saenko, I., Skorik, F., \& Bushuev, S. (2015, May). Neural network approach to forecast the state of the internet of things elements. In 2015 XVIII international conference on soft computing and measurements (SCM) (pp. 133-135). IEEE.

[44]. Do, C. T., Douzal-Chouakria, A., Marié, S., \& Rombaut, M. (2015, August). Multiple Metric Learning for large margin kNN Classification of time series. In 2015 23rd European Signal Processing Conference (EUSIPCO) (pp. 2346-2350). IEEE.

[45]. Shukla, M., Kosta, Y. P., \& Chauhan, P. (2015, September). Analysis and evaluation of outlier detection algorithms in data streams. In 2015 International Conference on Computer, Communication and Control (IC4) (pp. 1-8). IEEE.

[46]. Souza, A. M., \& Amazonas, J. R. (2015). An outlier detect algorithm using big data processing and internet of things architecture. Procedia Computer Science, 52, 1010-1015.

[47]. Tao, X., \& Ji, C. (2014, November). Clustering massive small data for iot. In The 2014 2nd International Conference on Systems and Informatics (ICSAI 2014) (pp. 974-978). IEEE.

[48]. Costa, C., \& Santos, M. Y. (2015). Improving cities sustainability through the use of data mining in a context of big city data.

[49]. Hromic, H., Le Phuoc, D., Serrano, M., Antonić, A., Žarko, I. P., Hayes, C., \& Decker, S. (2015, June). Real time analysis of sensor data for the internet of things by means of clustering and event processing. In 2015 IEEE International conference on communications (ICC) (pp. 685-691). IEEE.

[50]. Monekosso, D. N., \& Remagnino, P. (2013). Data reconciliation in a smart home sensor network. Expert Systems with Applications, 40(8), 3248-3255.

[51]. Ramalho, F., Neto, A., Santos, K., \& Agoulmine, N. (2015, October). Enhancing ehealth smart applications: A fog-enabled approach. In 2015 17th international conference on Ehealth networking, application \& services (HealthCom) (pp. 323-328). IEEE. 